\title{
Pesquisa musicológica e acesso à informação
}

\author{
Pablo Sotuyo Blanco, Pablo Iglesias Magalhães, Pedro Ivo Araújo \\ Universidade Federal da Bahia | Orcid: 0000-0002-3987-2944 \\ Universidade Federal do Oeste da Bahia Orcid: 0000-0001-5590-3889 \\ NEMUS-UFBA Orcid: 0000-0001-7551-7184
}

\begin{abstract}
Resumo
A partir das pesquisas e açôes musicológicas desenvolvidas pelo Núcleo de Estudos Musicológicos da Universidade Federal da Bahia (NEMUS-UFBA), apresentaremos algumas consideraçóes relativas às inevitáveis relaçóes entre a Lei de Acesso à Informação (Lei No 12.527, de 18 de novembro de 2011) e a pesquisa no campo das Ciências Humanas e Sociais (aplicadas ou não), sobretudo no que diz respeito às formas em que as instituições de ensino superior (em diante IES) propiciam o cumprimento dessa lei visando garantir o direito cidadão, não apenas de simples acesso ao corpo informacional vinculado à pesquisa, mas também de efetivar eventuais corroboraçóes dos resultados oportunamente apresentados. Nesse sentido, serão também apresentadas ao público, novas ferramentas desenvolvidas pelo NEMUS -UFBA durante 2020, no intuito de fortalecer tanto a pesquisa musicológica quanto a sua transparência.

Palavras-Chave: Ciências Humanas e Sociais, Pesquisa em música, Acesso à informação.
\end{abstract}

\section{Musicological research and access to information}

\begin{abstract}
Based on the research and musicological actions developed by the Center for Musicological Studies of the Federal University of Bahia (NEMUS-UFBA), we will present some considerations regarding the inevitable relations between the Access to Information Law (Law No. 12,527, of November 18, 2011) and research in the field of Human and Social Sciences (applied or not), especially with regard to the ways in which higher education institutions (hereinafter HEI) provide compliance with this law in order to guarantee the citizen's right, not just simple access to the body of information linked to the research, but also to carry out any corroboration of the results presented in due course. In this sense, new tools developed by NEMUS-UFBA during 2020 will also be presented to the public, in order to strengthen both musicological research and its transparency.
\end{abstract}

Keywords: Humanities and Social Sciences, Music research, Access to information.

\section{Investigación musicológica y acceso a la información}

\section{Resúmen}

A partir de las investigaciones y acciones musicológicas desarrolladas por el Núcleo de Estudios Musicológicos de la Universidad Federal de Bahía (NEMUS-UFBA), presentaremos algunas consideraciones sobre las inevitables relaciones entre la Ley de Acceso a la Información (Ley N ${ }^{\circ}$ 12.527, de 18 de noviembre). , 2011) y la investigación en el campo de las Ciencias Humanas y Sociales (aplicadas o no), especialmente en lo que respecta a las formas en que las instituciones de educación superior (en adelante IES) dan cumplimiento a esta ley con el fin de garantizar el derecho ciudadano, no solo de acceso al cuerpo de información vinculado a la investigación, sino también para realizar cualquier corroboración de los resultados presentados en su momento. En este sentido, también se presentarán al público las nuevas herramientas desarrolladas por el NEMUS-UFBA durante 2020, con el fin de fortalecer tanto la investigación musicológica como su transparencia.

Palabras Clave: Ciências Humanas y Sociales, Investigación em música, Acceso a la informação. 


\section{Introduçáo}

A partir da experiência adquirida e do conhecimento acumulado no campo da musicologia e da ciência da informação aplicada em música, pretende-se discutir aqui quais os caminhos possíveis para resolver (ou mesmo evitar) alguns dos problemas detectados na realização, divulgação e necessária corroboração dos resultados de pesquisas em musicologia e, por extensão, nas ciências sociais.

De início, deve-se esclarecer que, no que diz respeito às áreas do conhecimento identificadas pelas agências brasileiras (notadamente a $\mathrm{CAPES}^{1}$ e o $\mathrm{CNPq}^{2}$ ), a musicologia (no seu sentido mais abrangente) náo existe, nem como campo nem como disciplina. Nem Não existe sequer como pesquisa em música. No âmbito que ela deveria estar inserida, as Ciências Humanas e Sociais, isto é, aquela área de conhecimento que estuda o homem enquanto ser gregário (seja social, cultural, etc.), não a encontramos.

A música (ou melhor dito, o fazer musical, técnico e eventualmente artístico, porém não explicitamente científico, musicológico) aparece junto com outras artes (cênicas e visuais), mas não todas. ${ }^{3}$ Uma singela e indireta referência à pesquisa em artes parece transparecer no âmbito dos Fundamentos e Crítica da Artes. No entanto, essa denominação (incluindo as três disciplinas na qual ela se desdobra ${ }^{4}$ ) parece estar mais próxima das artes visuais do que das outras artes.

Nesse mesmo descompasso, porém em sentido oposto, se encontra a pesquisa em História, já que ela não apenas tem sua própria área devidamente identificada, mas perpassa as mais diversas áreas como disciplina aplicada, desde o Direito, Sociologia, Economia, Arquitetura, Urbanismo, Psicologia Educação e Teologia.

Como veremos, essa falta de consistência e coerência na organizaçáo brasileira do conhecimento gera uma série de problemas (e, consequentemente, vícios correlatos) fundamentalmente pelo seu efeito contrário: o desconhecimento do que é pesquisa, tanto em geral quanto especificamente em música, notadamente musicológica, seja pelo seu viés teórico, cultural, histórico, antropológico, cognitivo, ou pedagógico, dentre outros. Dentre as consequências que tais carências acarretam para a área, pode-se incluir uma série de falhas de natureza diversa que, no passado e no presente, atingiram (e alguns ainda atingem) a nossa produção científica e que podem ser reunidas em três grupos: a) as processuais; b) as intelectuais; e c) as comportamentais. (Quadro 1)

1 Disponível em <https://www.gov.br/capes/pt-br/acesso-a-informacao/acoes-e-programas/ avaliacao/ instrumentos/documentos-de-apoio-1/tabela-de-areas-de-conhecimento-avaliacao $>$.

2 Disponível em $<$ http://lattes.cnpq.br/documents/11871/24930/TabeladeAreasdoConhecimento.pdf/d192ff6b-3e0a-4074-a74d-c280521bd5f7>

3 As referidas tabelas também não identificam explicitamente as artes literárias (poesia, romance, dramaturgia, por exemplo), embora a organização da área de Letras, ao se estruturar em torno da diversidade do seu objeto de estudo (línguas e literaturas) pareça ter resolvido os problemas que a pesquisa em música enfrenta.

$4 \quad$ Teoria da Arte, História da Arte, Crítica da Arte. (cf. BRASIL, 2021a). 
Quadro 1 - Relação das falhas nas Ciências Humanas e Sociais

\begin{tabular}{|l|l|}
\hline \multirow{2}{*}{ NÍVEL } & TIPO \\
\hline \multirow{4}{*}{ Processual } & Desatualização em revisão bibliográfica \\
\cline { 2 - 2 } & Inconsistência processual investigativa (teórica, metodológica, analítica) \\
\hline \multirow{5}{*}{ Comportamental } & Equívocos relativos aos campos de pesquisa e suas epistemes \\
\cline { 2 - 2 } & Desconhecimento de taxonomias e tipologias (documentais, por exemplo) \\
\cline { 2 - 2 } & Distorção de conceitos oriundos de outras áreas, campos e/ou disciplinas \\
\hline & "Caudilhismo" profissional e exclusivismo da pesquisa \\
\cline { 2 - 2 } & Reserva de mercado intelectual, ideológica e profissional \\
\cline { 2 - 2 } & Colecionismo e fetichismo ontológicos (fontes documentais) \\
\cline { 2 - 2 } & Construção de discursos (enviesados) sem fundamento \\
\cline { 2 - 2 } & Manipulação de resultados e ocultaçáo de fontes \\
\cline { 2 - 2 } & Outros problemas éticos na prática profissional \\
\hline
\end{tabular}

Fonte: Elaborado pelos autores.

Com relação a alguns dos problemas e falhas acima relacionados, desde finais do século XX, as ciências humanas e sociais vêm tentando superar algumas dessas questóes problemáticas, tanto em nível (multi)disciplinar quanto das classes profissionais envolvidas. Tais processos dizem fundamentalmente respeito à questóes de nível comportamental, assim tentando resolver:

1. O "caudilhismo" profissional e o exclusivismo das pesquisas. As grandes figuras individuais (e por vezes, individualistas) do passado vem sendo gradualmente substituídas por grupos de pesquisa mais cooperativos, promovendo um número cada vez maior de publicações em coautoria, assim fomentando a integração do campo, eliminando o velho e ultrapassado sentimento da propriedade exclusiva das pesquisas. ${ }^{5}$

2. A reserva de mercado intelectual, ideológica e profissional (com manifestaçóes e resultados encampados no favorecimento, na corrupção e no patrimonialismo particular, não institucional), prática que busca favorecer pesquisas e pesquisadores associados a determinado grupo, ignorando propositadamente pesquisas, fontes e resultados, também isolando pesquisadores por motivação pessoal, intelectual ou ideológica (criando assim verdadeiros “currais” de referências), práticas facilmente vinculáveis ao acima mencionado caudilhismo e seus autodenominados "herdeiros" . ${ }^{6}$ Em casos extremos, essa prática leva à apropriação do patrimônio e à corrupção, com vistas à ascensão de carreiras de coligados, em detrimento da legislação e do princípio de isonomia. Corrupção e favorecimento são difíceis de se combater em ambiente acadêmico, na medida em que "a legislação [do país] não deve tentar incluir sançóes à corrupção acadêmica individual, seja de aluno, seja de docente" (HEYNEMAN, 2014). Para confrontar essas práticas tóxicas, parte da

5

6 meio de suas redes pessoais e institucionais, os acadêmicos produzem bens simbólicos, incluindo estudos, com o objetivo de serem consumidos (e citados) por seus próprios pares, sendo, ao mesmo tempo, produtores e consumidores dos próprios bens e dos bens dos outros, induzindo com que os pesquisadores dependam do reconhecimento pelos seus colegas (BOURDIEU, 1974, p. 108). 
nova geração de pesquisadores vem estimulando uma maior interação crítica entre os autores, promovendo sérios debates acadêmicos no âmbito das mídias sociais, assim como fomentando a prática de resenhas (embora ainda incipiente) publicadas no crescente parque editorial científico no Brasil.

3. O colecionismo e fetichismo documentais por parte de pesquisadores, geralmente acompanhados por desnecessários deslocamentos documentais (em prol de coleçóes particulares ou privadas), assim como de importante grau de desvios na prática profissional por parte dos responsáveis pelo acesso às fontes, quando em âmbitos institucionais. ${ }^{7}$ Tanto a crescente tendência à patrimonialização institucional pública dos acervos documentais privados quanto a gradativa renovação dos quadros profissionais nas CHS quanto das ciências sociais aplicadas, resultaram não apenas na atualização dos marcos regulatórios que definem os processos de incorporação institucional de acervos documentais (garantindo a preservação e o livre acesso aos mesmos - inclusive os musicais), mas também no fomento de condutas profissionais, nas instituições de custodia desses acervos, muito mais imparciais e transparentes com relação ao acesso às fontes documentais. ${ }^{8}$

4. É mister considerar também que boa parte dessas mudanças vem sendo promovida, sustentada e realizada não apenas no nível institucional acadêmico, mas também no nível das associaçôes de classe profissional, tais como Associação Nacional de História (ANPUH), Associação Brasileira de Antropologia (ABA), Associação Nacional de Pesquisa e Pós-graduação em Música (ANPPOM), Associação Brasileira de Musicologia (ABMUS), dentre outras. Esse processo alcança também as Ciências Sociais Aplicadas, enquanto campo de conhecimento interdisciplinar, voltado para os aspectos sociais das diversas realidades humanas, dentre cujas disciplinas afetadas pelas iniciativas acima referidas se incluem a Biblioteconomia e a Arquivologia (notadamente quando aplicadas à música).

No entanto, com relação às falhas ainda presentes, sobretudo no âmbito das instituições de ensino, cabe perguntar: o que fazer? Como prevenir ou evitar as falhas processuais, intelectuais ou comportamentais? Nesse sentido, observamos que o desenvolvimento e efetivação de políticas institucionais proativas, promovendo a atualização na capacitação docente (incluindo seus aspectos técnicos e jurídicos correlatos), visando uma formação melhorada dos estudantes (assim objetivando prevenir as referidas falhas), junto com o fortalecimento de açôes estruturantes e infraestruturais já em andamento, incluindo a promoção e ampliação do diálogo no âmbito da Comissão Nacional de Ética na Pesquisa (CNEP) se apresentam como alternativas claras, efetivas e muito eficazes.

Nesse contexto em transformação nas Ciências Humanas e Sociais junto às Sociais Aplicadas (em diante CHSSA), pode-se observar que a pesquisa musicológica (isto é, toda e qualquer pesquisa relativa à música desenvolvida nas suas diversas e múltiplas subáreas) não diverge, em geral, de outros tipos de pesquisa. Ela costuma tanto reunir documentos preexistentes (durante a coleta de dados) quanto produzir documentos novos, sobretudo durante o processamento e análise crítica dos dados constantes nos documentos anteriores,

$7 \quad$ cf. GREENHALGH, 2014.

$8 \quad$ cf. COTTA, 1997; 2000; 2007; 2011. 
assim como na disseminação dos seus resultados de pesquisa. Ambos conjuntos documentais podem incluir documentos textuais, musicográficos, audiovisuais, sonoros e iconográficos, isto é, praticamente todos os gêneros documentais segundo definidos pela Ciência da Informação. ${ }^{9}$

A fim de evitar as falhas acima apontadas (e outras que eventualmente possam vir a acontecer), precisamos fortalecer os mecanismos de controle social da pesquisa, sobretudo aquele exercido por pares acadêmicos. Somente o fortalecimento da transparência na pesquisa permitirá promover o reconhecimento (nacional e internacional) das CHSSA. Para poder atingir tais objetivos é necessário poder checar as pesquisas e os dados processados; para isso, deve-se ter acesso aos documentos, tanto os preexistentes quanto os produzidos pela pesquisa. Consequentemente, essa documentação deve ficar disponível para consulta.

Nesse sentido, existem dispositivos no Brasil que, de início, podem ajudar nesta situação para o bem das ciências humanas, notadamente a desenvolvida nas instituiçóes de ensino superior em território nacional. Nos referimos aos diversos marcos regulatórios aplicáveis à pesquisa em CHSSA no país.

\section{Marcos regulatórios aplicáveis à pesquisa em CHSSA no Brasil}

Falando em termos amplos, além dos necessários marcos teóricos, metodológicos e técnicos previstos e necessários em qualquer pesquisa, o Brasil conta com um conjunto de marcos regulatórios relativos a diversos aspectos da vida social, que poderiam (e deveriam) ser mais frequentemente aplicados à pesquisa no país. (Quadro 2)

No entanto, caberia observar em que grau eles são reconhecidos, atendidos e aplicados nos âmbitos das instituiçóes de ensino superior. Segundo tudo indica, em termos gerais, as referidas instituiçóes com certeza reconhecem ditos marcos regulatórios, porém, nem todos são devidamente aplicados e/ou atendidos e, quando o são, tais eventos não constituem prática corriqueira. Isto é... Nem todos, nem sempre... Notadamente nas instâncias em que a pesquisa é promovida, desenvolvida e disseminada, seja na iniciação científica vinculada à graduação ou nos programas de pós-graduação, dentre outros.

Dentre os marcos arrolados no Quadro 2, é preciso nos debruçarmos sobre os mecanismos de transparência controlada previstos na Lei de Acesso à Informação que, em nosso parecer, pode auxiliar fortemente no objetivo de garantir a corroboração e verificação da pesquisa em CHSSA. 
Quadro 2 - Relação dos marcos regulatórios aplicáveis à pesquisa e sua corroboração

\begin{tabular}{|l|l|l|}
\hline ETAPA & MARCO REGULATÓRIO & OBSERVAÇÓES \\
\hline \multirow{5}{*}{ PREPARAÇÃO } & Marcos Teóricos e Metodológicos & Adequados aos objetivos \\
\cline { 2 - 3 } & $\begin{array}{l}\text { CNEP/CONEP (2012) e CEPH } \\
\text { (e seus diversos termos) }\end{array}$ & $\begin{array}{l}\text { No caso de pesquisas com } \\
\text { seres humanos vivos (ex. } \\
\text { entrevistas, etc.) }\end{array}$ \\
\hline \multirow{5}{*}{ DESENVOLVIMENTO } & Constituição Federal (1988) & Marco geral \\
\cline { 2 - 3 } & Lei de Direitos Autorais (n. 9.610 - 1998) & Marco geral e patrimonial \\
\cline { 2 - 3 } & $\begin{array}{l}\text { Lei Geral de Proteçáo de Dados Pessoais } \\
\text { (n. 13.709 de 2019) }\end{array}$ & $\begin{array}{l}\text { No caso de pesquisas } \\
\text { com seres humanos } \\
\text { vivos e desenvolvimentos } \\
\text { informáticos online }\end{array}$ \\
\hline \multirow{5}{*}{ DIVULGAÇÃO } & Marcos técnicos & $\begin{array}{l}\text { Oriundos da } \\
\text { Biblioteconomia, } \\
\text { Arquivologia e TICs }\end{array}$ \\
\cline { 2 - 3 } & Declaração de Berlim (2003) & Brasil assinou em 2006 \\
\cline { 2 - 3 } & Constituição Federal (1988) & Marco geral \\
\cline { 2 - 3 } & Lei de Direitos Autorais (n. 9.610 - 1998) & Marco geral e patrimonial \\
\cline { 2 - 3 } & $\begin{array}{l}\text { Lei Acesso à Informação (n. 12.527 - 2011) } \\
\text { e Decreto n. 7.724 (2012) }\end{array}$ & $\begin{array}{l}\text { Marco de transparência } \\
\text { controlada }\end{array}$ \\
\cline { 2 - 3 } & $\begin{array}{l}\text { Lei Geral de Proteção de Dados Pessoais } \\
\text { (n. 13.709 de 2019) }\end{array}$ & $\begin{array}{l}\text { No caso de pesquisas } \\
\text { com seres humanos } \\
\text { vivos e desenvolvimentos } \\
\text { informáticos online }\end{array}$ \\
\hline
\end{tabular}

Fonte: Elaborado pelos autores.

\section{A Lei de Acesso à Informação: auxílio à transparência em pesquisa \\ O direito à informação consta no Artigo $5^{\circ}$ da Constituição Federal de 1988,} tanto no seu inciso XIV quanto no inciso XXXIII, no qual inequivocamente declara que "todos têm direito a receber dos órgáos públicos informaçôes de seu interesse particular, ou de interesse coletivo ou geral, que serão prestadas no prazo da lei, sob pena de responsabilidade" (BRASIL, 1988). No entanto, esse direito fundamental de todos os brasileiros ficou sem a devida regulamentaçáo durante 23 anos, até 2011, quando a Lei 12.527 foi promulgada. Segundo Resende (2019)

As políticas de transparência pública e, em especial, a Lei de Acesso à Informação, são uma das inovaçóes mais importantes do Estado brasileiro nos últimos anos. Todavia, poucos trabalhos buscaram explicar sua origem e desenvolvimento. Há maior ênfase nos interesses, estratégias e cálculos dos atores políticos envolvidos, agindo no interior do Estado. Outros estudos, por sua vez, enfatizaram a influência de grupos e organizaçóes da sociedade civil nacional e internacional nesse processo. Considerando o longo histórico da cultura (ou do paradigma) do sigilo relacionado aos assuntos de Estado no Brasil, a pesquisa [de Resende] explora a questão sob outra perspectiva, visando compreender como, nas últimas décadas, ideias relacionadas ao direito à informação pública em seus múltiplos significados foram mobilizadas por atores envolvidos com o tema, e como convergiram para demandas por maior acesso da sociedade à informaçấo detida pelo Estado brasileiro. Isso contribuiu para construir novas políticas e instituiçôes relacionadas à transparência governamental. 
Embora bastante utilizado quando a pesquisa está dirigida a dados gerados no âmbito governamental (cf. AZEVEDO; MAIA, 2019), ele parece ser completamente desconhecido (ou até ignorado) pela comunidade acadêmica quando da corroboração da pesquisa se trata. Em virtude dessa falta de compreensão dos possíveis alcances reguladores da Lei de Acesso à Informação No 12.527 de 2011 (em diante LAI), nos assistindo generosamente na necessária corroboração da pesquisa em CHSSA, faremos uma descrição detalhada e comentada dos seus diversos aspectos, da forma mais didática possível.

\section{Alcance institucional, diretrizes e objeto da LAI}

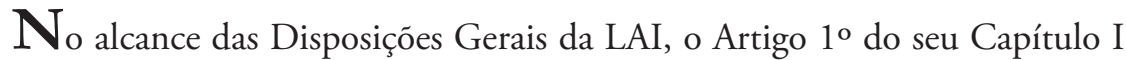
declara: "Esta Lei dispóe sobre os procedimentos a serem observados pela União, Estados, Distrito Federal e Municípios, com o fim de garantir o acesso a informaçóes previsto no inciso XXXIII do art. $5^{\circ}$, no inciso II do $\$ 3^{\circ}$ do art. 37 e no $\$ 2^{\circ}$ do art. 216 da Constituição Federal." (BRASIL, 2011a). Nesse sentido, o texto da LAI ainda informa:

Parágrafo único. Subordinam-se ao regime desta Lei:

I - os órgáos públicos integrantes da administração direta dos Poderes Executivo, Legislativo, incluindo as Cortes de Contas, e Judiciário e do Ministério Público;

II - as autarquias, as fundaçóes públicas, as empresas públicas, as sociedades de economia mista e demais entidades controladas direta ou indiretamente pela União, Estados, Distrito Federal e Municípios.

Art. $2^{\circ}$ - Aplicam-se as disposiçôes desta Lei, no que couber, às entidades privadas sem fins lucrativos que recebam, para realizaçáo de açôes de interesse público, recursos públicos diretamente do orçamento ou mediante subvençôes sociais, contrato de gestáo, termo de parceria, convênios, acordo, ajustes ou outros instrumentos congêneres. (BRASIL, 2011a. Grifos nossos)

Esse âmbito institucional tão amplo e, ao mesmo tempo, precisa e claramente definido, segundo informa o artigo $3^{\circ}$, é exigido de desenvolver práticas condizentes com os objetivos da lei, incluindo publicidade, divulgaçấo e fomento da cultura da transparência e do controle social.

Art. $3^{\circ}$ Os procedimentos previstos nesta Lei destinam-se a assegurar o direito fundamental de acesso à informação e devem ser executados em conformidade com os princípios básicos da administração pública e com as seguintes diretrizes:

I - observância da publicidade como preceito geral e do sigilo como exceção;

II - divulgaçâo de informaçôes de interesse público, independentemente de solicitaçôes;

III - utilização de meios de comunicação viabilizados pela tecnologia da informação; 
IV - fomento ao desenvolvimento da cultura de transparência na administraçáo pública;

$\mathrm{V}$ - desenvolvimento do controle social da administração pública. (BRASIL, 2011a)

Assim, a LAI visa não apenas garantir o direito de acesso à informação produzida ou acumulada no âmbito institucional por ela definido, mas também promover a consciência dos seus benefícios entre os cidadãos. Ainda, ela define claramente alguns marcos conceituais para uma melhor compreensão do seu alcance, segundo exposto no artigo $4^{\circ}$, do qual citamos apenas os três conceitos mais relevantes ao tema aqui proposto, dentre os nove que o integram.

Art. 4o Para os efeitos desta Lei, considera-se:

I - informação: dados, processados ou não, que podem ser utilizados para produção e transmissáo de conhecimento, contidos em qualquer meio, suporte ou formato;

II - documento: unidade de registro de informaçóes, qualquer que seja o suporte ou formato; [...]

$\mathrm{V}$ - tratamento da informação: conjunto de açóes referentes à produção, recepção, classificação, utilização, acesso, reprodução, transporte, transmissão, distribuição, arquivamento, armazenamento, eliminação, avaliação, destinação ou controle da informação; [...] (BRASIL, 2011a. Grifos nossos) ${ }^{10}$

\section{Das formas de acesso ao objeto da LAI}

As informaçóes e dados acima referidos, processados ou não, registrados em documentos e tratados de diversas maneiras, constituem aquilo ao que se precisa ter acesso a fim de corroborar qualquer pesquisa. $\mathrm{O}$ alcance desse acesso consta bem explicado no seu artigo $7^{\circ}$.
Art. $7^{\circ} \mathrm{O}$ acesso [...] compreende, [...] os direitos de obter:
I - orientação [sobre procedimentos e local da informação almejada];
II - informação contida em registros ou documentos [...];
III - informação produzida ou custodiada por pessoa física ou entidade privada decorrente de qualquer vínculo com seus órgãos ou entidades, mesmo que esse vínculo já tenha cessado;

\footnotetext{
$10 \mathrm{O}$ artigo $4^{\circ}$ inclui, dentre outros conceitos relativos (tais como disponibilidade, autenticidade, integridade e primariedade), especificaçôes sobre tipos de informação - sigilosa ou pessoal - as quais sã regulamentadas tanto pelo Decreto no 7.724, de 16 de maio de 2012, quanto pela Lei ${ }^{\circ} 13.709$, de 14 de agosto de 2018 respectivamente, assim como eventualmente protegidas por termos e anuências específicos, principalmente emergidos na avaliação dos projetos de pesquisa no âmbito do CNEP.
} 
IV - informação primária, íntegra, autêntica e atualizada;

V - informação sobre atividades exercidas [...];

VII - informação relativa: a) à implementação, acompanhamento e resultados dos programas, projetos e açóes [...]; (BRASIL, 2011a. Grifos nossos).

Ainda, o artigo $9^{\circ}$ estabelece algumas das formas básicas de garantir o acesso à informação, seja pela "criação de serviço de informaçôes" ou pela "realização de audiências ou consultas públicas, incentivo à participação popular ou a outras formas de divulgação.” (BRASIL, 2011a. Grifos nossos)

Por sua vez, a Seção I do Capítulo III - Do procedimento de acesso à informação, estabelece nos seus artigos $10^{\circ}$ a $14^{\circ}$ as condiçóes e características do pedido de acesso e seu atendimento.

Art. 10. Qualquer interessado poderá apresentar pedido de acesso a informaçôes aos órgáos e entidades referidos no art. $1^{\circ}$ desta Lei, por qualquer meio legítimo, devendo o pedido conter a identificação do requerente e a especificação da informação requerida.

$\$ 1^{\circ}$ Para o acesso a informaçóes de interesse público, a identificação do requerente não pode conter exigências que inviabilizem a solicitação.

$\$ 2^{\circ}$ Os órgãos e entidades do poder público devem viabilizar alternativa de encaminhamento de pedidos de acesso por meio de seus sítios oficiais na internet.

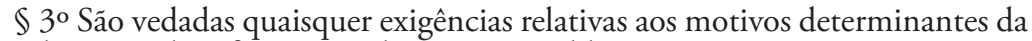
solicitação de informações de interesse público.

\section{Art. 11. O órgáo ou entidade pública deverá autorizar ou conceder o acesso imediato à informação disponível.}

$\$ 1^{\circ}$ Náo sendo possível conceder o acesso imediato, na forma disposta no caput, o órgão ou entidade que receber o pedido deverá, [...] [agendar consulta, explicar motivos e, se for o caso, orientar o usuário] [...]

Art. 12. O serviço de busca e fornecimento da informação é gratuito, [...]

Art. 13. Quando se tratar de acesso à informação contida em documento cuja manipulação possa prejudicar sua integridade, deverá ser oferecida a consulta de cópia, com certificação de que esta confere com o original.[...]

Art. 14. É direito do requerente obter o inteiro teor de decisão de negativa de acesso, por certidão ou cópia. (BRASIL, 2011a. Grifos nossos)

Assim estabelecidos os marcos e recursos principais da LAI, resta perguntar: o que as IES e demais instituições de pesquisa correlatas fazem com relação a tudo isto? Além da implementação dos recursos básicos e "Acesso à informação" nos diversos portais, no que diz respeito à possível corroboração da pesquisa em CHSSA, concordamos com Azevedo e Maia, quando observam que os recursos são insuficientes, equivocados e, por vezes, até 
intimidatórios gerando assim diversos obstáculos para os usuários. Segundo Azevedo e Maia (2019), os principais obstáculos encontrados pelos usuários, incluem:

1) localização da aba, ícone ou menu que direcione ao "acesso à informação" nos portais estaduais, que em muitas vezes apresentam excessos de informação institucional ou se confundem com o menu "transparência";

2) realização do cadastro dos dados pessoais do requerente em todos os órgãos selecionados para a pesquisa, em que a finalizaçáo do cadastro está condicionada ao preenchimento de diversos campos obrigatórios, tais como: nome de usuário, senha de acesso, nome completo, $\mathrm{CPF}, \mathrm{RG}$, órgão expedidor, data de nascimento, e-mail, telefone fixo, celular, todos os campos de endereço, profissão, instituição, dentre outros;

3) dificuldades no processo de solicitação de informação, no qual o usuário não possui orientaçóes sobre qual órgão está subordinado à instituição de interesse;

4) inoperabilidade dos sistemas e-Sics, ${ }^{11}$ ouvidorias e formulários, que em alguns casos não geram números de protocolos nem finalizam o registro; e

5) retorno e notificação das respostas oficiais dos órgãos.

Perante essa situação, novamente indagamos: o que as instituições em questão fazem com isso? Reconhecem, com certeza... No entanto, nem sempre se encontram dispostas a aplicar a LAI em toda a sua extensão, tendendo a relegar as diversas responsabilidades nos pesquisadores (de quem são parceiros). Ainda alegam falta de meios para custodiar as fontes documentais que sustentam as pesquisas, embora nem sempre seja questão de recursos financeiros, especificamente.

A simples invocação da LAI pelo interessado, obriga às instituiçôes a garantir a guarda e disponibilização para consulta dessa documentação, assim como garantir o acesso não apenas aos resultados publicados, mas a totalidade da documentaçấo correlata (preexistente e produzida) que deu sustento e base às pesquisas produzidas.

\section{Da negativa do acesso à informaçáo e das responsabilidades}

O que implicaria não atender à LAI? Não dar acesso às informaçôes relativas à pesquisa significa muito mais do que apenas cercear um direito fundamental dos cidadãos e não permitir a verificação e/ou corroboração das mesmas. Significa minar a credibilidade e transparência do campo científico, comprometer a idoneidade da pesquisa e da instituiçáo a ela vinculada, assim como, em última instância, atentar contra a cidadania sociocultural da população vinculada (direta ou indiretamente) à pesquisa, socavando a sua identidade, autoestima e potencial de crescimento.

Mas... Quem controla a aplicação da LAI nas instituiçóes de pesquisa em CHSSA? Segundo o texto da lei estabelece no seu artigo $40^{\circ}$, "o dirigente máximo de cada órgão ou entidade da administração pública federal direta e indireta designará autoridade que lhe seja diretamente subordinada" (BRASIL, 2011a) para, no âmbito do respectivo órgão ou

11 Refere ao Sistema Eletrônico de Informaçōes ao Cidadão (e-SIC) desenvolvido no âmbito da LAI em conjunto com as de governança eletrônica no Brasil. 
entidade, exercer as seguintes atribuições:

I - assegurar o cumprimento das normas relativas ao acesso à informaçáo, de forma eficiente e adequada aos objetivos desta Lei;

II - monitorar a implementaçáo do disposto nesta Lei e apresentar relatórios periódicos sobre o seu cumprimento;

III - recomendar as medidas indispensáveis à implementação e ao aperfeiçoamento das normas e procedimentos necessários ao correto cumprimento do disposto nesta Lei; e

IV - orientar as respectivas unidades no que se refere ao cumprimento do disposto nesta Lei e seus regulamentos. (BRASIL, 2011a. Grifos nossos)

Por sua vez, segundo o Artigo 410 "O Poder Executivo Federal designará órgão da administração pública federal responsável [...] III - pelo monitoramento da aplicação da lei no âmbito da administração pública federal" (BRASIL, 2011a. Grifos nossos) que, logicamente recai atualmente no Ministério da Transparência, Fiscalização e Controladoria-Geral da Uniāo. Finalmente, a instância do controle social é, evidentemente, exercida pela cidadania interessada.

No simples caso de negar o acesso à documentação requerida sem fundamentação devida, a LAI inclui expressas advertências, tipificaçôes, enquadramentos e as correspondentes sançôes, em diversos artigos. Assim, os artigos $7^{\circ}$ e $8^{\circ}$ adiantam algumas advertências.

Art. 70 [...]

$\$ 4^{\circ} \mathrm{A}$ negativa de acesso às informaçōes objeto de pedido formulado aos órgãos e entidades referidas no art. $1^{\circ}$, quando não fundamentada, sujeitará o responsável a medidas disciplinares, nos termos do art. 32 desta Lei.

$\$ 5^{\circ}$ Informado do extravio da informaçáo solicitada, poderá o interessado requerer à autoridade competente a imediata abertura de sindicância para apurar o desaparecimento da respectiva documentação. [...]

Art. $8^{\circ}$ É dever dos órgãos e entidades públicas promover, independentemente de requerimentos, a divulgação em local de fácil acesso, no âmbito de suas competências, de informaçōes de interesse coletivo ou geral por eles produzidas ou custodiadas. [...]

$\$ 2^{\circ}$ Para cumprimento do disposto no caput, os órgãos e entidades públicas deverão utilizar todos os meios e instrumentos legítimos de que dispuserem, sendo obrigatória a divulgaçấo em sítios oficiais da rede mundial de computadores (internet). (BRASIL, 2011a. Grifos nossos)

Por sua vez, os artigos $32^{\circ}$ e $33^{\circ}$ expóem claramente as responsabilidades e sanções previstas em caso de recusa, ocultamento, uso ou classificação indevida, ou até mesmo de destruição da informação, dolo ou má-fé. 
Art. 32. Constituem condutas ilícitas [...]:

I - recusar-se a fornecer informação requerida [...], retardar o seu fornecimento ou fornecê-la intencionalmente de forma incorreta, incompleta ou imprecisa;

II - utilizar indevidamente, bem como subtrair, destruir, inutilizar, desfigurar, alterar ou ocultar, total ou parcialmente, informação que se encontre sob sua guarda ou a que tenha acesso ou conhecimento em razáo do exercício das atribuiçóes de cargo, emprego ou função pública;

III - agir com dolo ou má-fé na análise das solicitaçôes [...];

V - impor sigilo à informação para obter proveito pessoal ou de terceiro, ou para fins de ocultação de ato ilegal cometido por si ou por outrem;

VI - ocultar da revisão de autoridade superior competente informação sigilosa para beneficiar a si ou a outrem, ou em prejuízo de terceiros; e

VII - destruir ou subtrair, por qualquer meio, documentos [...]

Art. 33. A pessoa física ou entidade privada que detiver informaçóes em virtude de vínculo de qualquer natureza com o poder público e deixar de observar o disposto nesta Lei estará sujeita às seguintes sançóes:

I - advertência;

II - multa;

III - rescisão do vínculo com o poder público;

IV - suspensão temporária de participar em licitação e impedimento de contratar com a administração pública por prazo não superior a 2 (dois) anos [...] (BRASIL, 2011a. Grifos nossos).

\section{Proposiçóes em prol da corroboraçáo de pesquisas em CHSSA}

Segundo previsto, dentre as diversas iniciativas e marcos normativos ligados à transparência, duas grandes tendências se destacam: a) a transparência ativa, com proposiçóes de divulgação proativa (sem necessidade de solicitação) em sítio eletrônico; e b) transparência passiva, que estabelece regras para solicitações de informação à instituição em questão.

Nesse sentido, as instituiçôes às quais este texto e a LAI contemplam, participam com ações concretas nessas duas tendências, porém com resultados diferentes. Em termos gerais, pode-se afirmar que praticamente todas elas contam com arquivos e bibliotecas onde as boas práticas dominam o fazer técnico e profissional. Muitas desenvolveram políticas de divulgação dos resultados de pesquisa (seja através dos diversos programas editorais ou dos repositórios institucionais, dentre outras estratégias), enquanto várias promovem a 
instalaçáo de acervos especializados. ${ }^{12}$ No entanto, quase nenhuma conta com políticas de recolhimento documental (nem sempre devidamente formalizadas e efetivadas) dos fundos acumulados durante as pesquisas. ${ }^{13}$

Por sua vez, dentre as diversas proposiçóes cabíveis em prol da promoção da corroboração de pesquisas desenvolvidas em âmbitos institucionais previstos na LAI, dentre as quais se incluem as IES, destacamos aqui aquelas que, quando efetivadas, poderão auxiliar na transformação positiva da atual situação:

- Informar, orientar e (ré)educar todos os recursos humanos a ela vinculados, incluídos pesquisadores, docentes, técnicos e estudantes;

- Promover a identificação e classificação adequada dos tipos documentais (preexistentes e produzidos na pesquisa) a serem guardados e preservados nos devidos processos correspondentes, fortalecendo assim a presença e participação de técnicos e pesquisadores profissionalmente atualizados, nos processos de gestâo e recolhimento documentais, devidamente adaptados aos gêneros, espécies e tipos documentais a serem processados; e

- Definir e garantir condições mínimas e suficientes de infraestrutura (alocando espaços adequados e desenvolvendo a tecnologia requerida), junto aos recursos humanos necessários, disponíveis e a ela destinados.

Nesse sentido, no campo da pesquisa em música, dentre as propostas em desenvolvimento e construção coletiva, em prol da melhoria das condiçóes gerais nos diversos níveis aqui observados, cabe referir as seguintes:

- Proposta de um código de ética e atividade profissional, apresentado na ANPPOM em 2006 e presentemente em desenvolvimento no âmbito da ABMUS;

- Aprovação das Diretrizes para a gestáo de documentos musicográficos em conjuntos musicais do âmbito público, aprovadas pelo Conselho Nacional de Arquivos em 2018 (cf. CONSELHO NACIONAL DE ARQUIVOS, 2018);

- Promoção de iniciativas internacionais em prol da identificação, indexação e pesquisa de fontes documentais relativas à música em solo brasileiro, tais como o RILM-Brasil (que lida com fontes musicográficas, estabelecido em 2005); RIdIM-Brasil (que lida com iconografia musical, estabelecido em 2008); e o capítulo brasileiro da Associação Internacional de Bibliotecas, Arquivos e Centros de Documentação em Música (IAML-Brasil, estabelecida em 2009) No compasso de todas essas iniciativas, o NEMUS-UFBA desenvolve e promove projetos de alcance nacional, dentre os quais podem-se destacar a construção e manutençáo de bancos de dados e outras ferramentas online de disseminação da informação musical e relativa à música. ${ }^{14}$

12 Exemplos disso podem ser encontrados na UFBA (ADoHM; Memorial de Dança), na UFMG (com o Acervo Curt Lange), na UFPel (e seu Centro de Documentação Musical), na UNICAMP (CIDDIC e CDMC), assim como na UnB, UCSAL, UFRJ, dentre muitas outras.

13 No âmbito da UFBA, o ADoHM vem promovendo a instalação, no fundo correspondente ao PPGMUS-UFBA, da série documental "Memória da pesquisa em música”, que atualmente guarda importante conjunto de dossiês contendo a documentação resultante de projetos de pesquisa em musicologia em nível de mestrado e doutorado.

14 Mais informação cf. http://www.nemus.ufba.br/ 


\section{Consideraçóes finais}

No encerramento deste texto, considerando os tempos que nos toca viver, é mister frisar a necessidade (e nosso empenho) de fortalecer a transparência e credibilidade dos campos científicos aqui em discussão, como mais uma forma de ratificar e enaltecer a idoneidade das pesquisas em CHSSA (particularmente em musicologia) e das instituiçōes de ensino superior a elas vinculadas.

Nesse sentido, acreditamos ter ressaltado a importância da LAI como mais uma ferramenta no controle social da pesquisa em CHSSA e, em particular, em música. Para isso, é preciso que as IES:

- Instruam seus pesquisadores, técnicos e alunos nos requerimentos consequentes à LAI, sobretudo no que diz respeito à guarda, preservação e recolhimento documental

- Se comprometam na implementação plena da LAI em todo o seu alcance, incluindo a ampliação e atualização dos seus planos de gestáo documental e disponibilização possível (classificação/descrição)

- Construam/desenvolvam condiçôes para a preservação da memória da pesquisa, e

- Visem o atendimento satisfatório dos usuários solicitantes.

Essas quatro açóes, acreditamos, constituem os pilares sobre os quais a LAI pode ser plenamente aproveitada como instrumento válido de fomento da cidadania sociocultural, sua identidade e autoestima. Afinal, parafraseando Emília Viotti da Costa... Um povo sem memória é um povo sem história... Não apenas carece de identidade e autoestima... carece de lugar na história... 


\section{Referências}

ARQUIVO NACIONAL. Dicionário brasileiro de terminologia arquivística. Rio de Janeiro: Arquivo Nacional, 2005. 232 p. (Publicações Técnicas, 41) Disponível em: www.conarq.arquivonacional.gov.br.

AZEVEDO, Rodolfo Almeida de; MAIA, Hemmilys Karolinne de Sousa. Reflexões sobre a utilizaçáo da Lei de Acesso à Informação para a pesquisa científica. Ciência da Informaçáo. v. 48 n. 3 (2019): Suplemento: Trabalhos apresentados na 10a Conferência Luso-Brasileira de Ciência Aberta - ConfOA. Disponível em: <http:// revista.ibict.br/ciinf/article/view/4752>. Acesso em 5 abr. 2021.

BATALHONE, Vitor; SANTOS, Evandro. (org.) Dossiê História e Ética - múltiplas e complexas dimensões de um problema historiográfico. História e Cultura, vol. 6, n. 3, Dezembro 2017.

BOURDIEU, Pierre. A economia das trocas simbólicas. São Paulo: Perspectiva, 1974.

BRASIL, Lei no 12.527, de 18 de novembro de 2011. Diário Oficial [da] República Federativa do Brasil, Brasília, DF, 18 dez. 2011 a.

, Controladoria-Geral da União. Acesso à Informação Pública: uma introduçáo à Lei n. 12.527/2011. Brasília: Imprensa Nacional, 2011b. Disponível em: <http:// www.acessoainformacao.gov.br/central-de-conteudo/publicacoes/ cartilhaacessoainformacao-1.pdf>. Acesso em 20 mai. 2021.

. Decreto n. 7.724, de 16 de maio de 2012. Regulamenta a Lei n. 12.527, de 18 de novembro de 2011, que dispóe sobre o acesso a informaçóes previsto no inciso XXXIII do caput do art. $5^{\circ}$, no inciso II do $\$ 3^{\circ}$ do art. 37 e no $\$ 2^{\circ}$ do art. 216 da Constituição.

, Ministério da Transparência, Fiscalização e Controladoria-Geral da União. Aplicação da Lei de Acesso à Informaçáo na Administraçáo Pública Federal. $2^{a}$ ed. Revista, atualizada e ampliada. Brasília, 2016. Disponível em <https://www. gov.br/acessoainformacao/pt-br/central-de-conteudo/publicacoes/arquivos/ aplicacao_lai_2edicao.pdf $>$.

, Ministério da Ciência, Tecnologia e Inovaçốes. Conselho Nacional de Desenvolvimento Científico e Tecnológico (CNPq). Tabela de Áreas do Conhecimento. [Brasília: CNPq, 2021a]. Disponível em: <http://lattes.cnpq.br/ documents/11871/24930/ TabeladeAreasdoConhecimento.pdf/d192ff6b-3e0a-4074-a74d-c280521bd5f7>. Acesso em 20 mai. 2021.

CASTAGNA, Paulo Augusto. Avanços e perspectivas na musicologia histórica brasileira. Revista do Conservatório de Música da UFPel, v. 1, p. 32-57, 2008.

CONSELHO NACIONAL DE ARQUIVOS. Diretrizes para a Gestáo de Documentos 
em Conjuntos Musicais do Âmbito Público. Rio de Janeiro: CTDAISM-CONARQ, 2018. Disponível em:http://conarq.gov.br/images/ctdais/diretrizes/Diretrizes_musicais_completa.pdf. Acesso em 04 abr. 2021.

COTTA, André Guerra. Acervos musicais brasileiros no século XXI e práticas musicais na América portuguesa: uma visão panorâmica e dois casos pontuais. In: LUCAS, Maria Elisabeth; NERY, Ruy Vieira (coords.) As músicas luso-brasileiras no final do antigo regime. repertórios, práticas e representaçóes. Lisboa: Fundação Calouste Gulbenkian, 2013. p. 29-58.

. Considerações sobre o direito de acesso às fontes primárias para a pesquisa musicológica. In: Anais do III Simpósio Latino-Americano de Musicologia. Curitiba: Fundaçáo Cultural de Curitiba, 1997.

. Novas consideraçóes sobre o acesso ao Patrimônio Musical no Brasil. Liinc em Revista, v. 7, p. 466-484, 2011.

. O Palimpsesto de Aristarco: Consideraçóes sobre plágio, originalidade e informação na musicologia histórica brasileira. ICTUS Periódico do PPGMUS-UFBA, v. 2, p. 07-36, 2000.

. História da Coleção Francisco Curt Lange. Tese (Doutorado em Música) Universidade Federal do Estado do Rio de Janeiro, UNIRIO, Rio de Janeiro, 2009. http:// www.repositorio-bc.unirio.br:8080/xmlui/handle/unirio/11504

GREENHALGH, Raphael Diego. Segurança contra roubo e furto de livros raros: uma perspectiva sob a ótica da economia do crime e da teoria da dissuasão. Tese (Doutorado em Ciência da Informação) Universidade de Brasília, Brasília, 2014. 2 v. https:// repositorio.unb.br/handle/10482/17800

HEYNEMAN, Stephen P. Corrupção acadêmica coloca ensino superior em risco. in: International Higher Education. Publicação trimestral do Center for International Higher Education / Boston College, n.75, 2014, pp.56-58.

RESENDE, João Francisco. A história das políticas de transparência no Brasil. Nexo. 24 de abr de 2019 (atualizado 30/04/2019 às 17h27). Disponível em: <https://www. nexojornal.com.br/academico/2019/04/24/A-hist\%C3\%B3ria-das-pol\%C3\%ADticas-de-transpar\%C3\%AAncia-no-Brasil>. Acesso em 14 mai 2021

SILVA, Anna Carollyna de Bulhóes Moreira; GARCIA, Joana Coeli Ribeiro. Lei de Acesso à Informação: a conduta ética e social sob o olhar das atribuiçôes profissionais do arquivista. Archeion Online, João Pessoa, v.4, n.2, p.03-24, jul./dez. 2016. http:// periodicos.ufpb.br/ojs2/index.php/archeion 